\title{
Socio-economic differences in fruit and vegetable consumption among middle-aged adults in France: adherence to the 'five-a-day' recommendation
}

\author{
C. Estaquio, N. Druesne-Pecollo, P. Latino-Martel, L. Dauchet, N. Arnault, S. Péneau, S. Hercberg \\ and S. Bertrais \\ UMR U557 INSERM/U1125 INRA/CNAM/PARIS 13 Université/Centre de Recherche en Nutrition Humaine -IdF, \\ Bobigny, France
}

\begin{abstract}
A high consumption of fruit and vegetables $(\mathrm{F} \& \mathrm{~V})$ has been associated with a lower incidence of many chronic diseases ${ }^{(1,2)}$. Increasing $\mathrm{F} \& \mathrm{~V}$ intake has become an international public health priority in many countries. The aim of the present study was to investigate relationships between socio-demographic and behavioural factors and both quantity and variety of F\&V consumption in a national sample of middle-aged French subjects.

The Supplementation en Vitamines et Mineraux Antioxydants (SU.VI.MAX) study ${ }^{(3)}$ included middle-aged adults (aged 45-60 years) who were followed for an 8 -year period. All subjects were invited to complete a $24 \mathrm{~h}$ dietary record every 2 months. The subjects selected were those who completed at least six dietary records during the first 2 years of follow-up and for whom data were available for all sociodemographic variables and behavioural characteristics. Furthermore, to take into account seasonal variations in F\&V consumption the sample was restricted to subjects having at least one-third of their reported $24 \mathrm{~h}$ dietary records in the autumn-winter period (NovemberApril) and one-third in the spring-summer period (May-October).

Older subjects, non-smokers and moderate alcohol consumers of both genders and women undertaking regular physical activity were more likely to achieve the 'five-a-day' F\&V recommendation. Educational level was associated with a higher quantity of F\&V in the study population. Men with a higher education level consumed a higher variety of $\mathrm{F} \& \mathrm{~V}$, whereas for women variety was significantly higher for vegetables only. No association was found with occupation in multivariate analyses for women, whereas higher fruit variety was observed for higher occupational categories for men. The contribution of $\mathrm{F} \& \mathrm{~V}$ to the cost of the total daily diet also differed between socio-economic groups, with some gender-specific relationships.

Most of the nutritional policies developed in Western countries to improve F\&V intakes are based on general actions for the whole population. However, low socio-economic groups should be targetted with specific actions to improve F\&V intake in low consumers.
\end{abstract}

1. Dauchet L, Amouyel P, Hercberg S \& Dallongeville J (2006) J Nutr 136, 2588-2593.

2. International Agency for Research on Cancer (2003) IARC Handbooks of Cancer Prevention. vol. 8: Fruits and Vegetables. Lyon, France: IARC.

3. Hercberg S, Galan P, Preziosi P, Bertrais S, Mennen L, Malvy D, Roussel AM, Favier A \& Briançon S (2004) Arch Intern Med 164, 2335-2342. 